\title{
Introduction: Negotiating Empowerment
}

\author{
Andrea Cornwall and Jenny Edwards
}

\begin{abstract}
This introductory article draws out some of the dimensions and dilemmas around women's empowerment that are highlighted in the articles in this IDS Bulletin: the choices, the negotiations, the narratives and above all, the context of women's lived experience. In doing so, we show that empowerment is a complex process that requires more than the quick and easy solutions often offered by development agencies. Much of the significant change happening in women's lives takes place outside of the range of these conventional interventions. In conclusion, we suggest that for development agencies to really support women's empowerment requires greater engagement with changing structures rather than accommodating women within the inequitable existing order, and a much deeper understanding of what makes change happen in their lives.
\end{abstract}

\section{Introduction}

Women's empowerment is heralded in today's development circles as a means that can produce extraordinary ends. Women are vaunted as a 'weapon against poverty' (DFID 2006: 1), their empowerment extolled as the solution to a host of entrenched social and economic problems. In response to this maelstrom of policy excitement, this issue of the IDS Bulletin is devoted to exploring what empowerment means in the everyday lives of women in different situations and circumstances. It draws on the work of an international network of researchers, the Pathways of Women's Empowerment Research Programme Consortium (RPC, hereafter 'Pathways'). ${ }^{1}$ Its aim is to bring fresh empirical and conceptual insights to an audience of development academics and policy actors, for whom 'women's empowerment' may be a familiar mantra, but one rarely accompanied by a consideration of the complexities of change or the lived realities of women's lives. ${ }^{2}$

The predominant image evoked by international development agencies when they talk of empowerment is of women gaining the (material) means to empower themselves as individuals, and putting this to the service of their families and communities. This tends to neglect what women are doing for and by themselves to bring about change in their own and other women's lives. The Pathways programme set out to look for these 'hidden' pathways, as well as at the better-known routes that those concerned with women's empowerment were promoting. Our interest is not just in individuals' pathways of change, nor only in what women are doing to change their own personal circumstances. Our exploration of pathways of positive change extends to collective action and institutionalised mechanisms that are aimed at changing structural relations as well as individual circumstances. We look beyond deliberate or planned intervention to try to gain a better understanding of what is happening in women's lives as a result of cultural, economic and other changes, such as the availability of new technologies such as mobile phones and satellite television. And as well as focusing on women's current opportunities and constraints, our work situates empowerment as a process in time, exploring change and continuities across generations.

Our focus in the first part of this IDS Bulletin is on mechanisms promoted by development agencies to enhance women's empowerment: electoral quotas, education, economic empowerment initiatives, legislative change and 
non-governmental public action. Contributors evaluate the extent to which these tools have had the kinds of effects that were intended or might be expected to produce. They reflect on what else might be needed to render them more effective in terms of their potential to transform. Our analysis draws attention to elements of empowerment initiatives that are often forgotten in the rush of easy promises: the sheer uphill struggle that is required to get hard-won policies and laws implemented.

The second section focuses on strategies for advocacy and mobilising used by women's organisations and movements. Here the focus is on challenges and contradictions, as well as stories of success and struggle. What emerges are powerful tales of the dedication and ingenuity of those who persist against all odds, the tactics that are resorted to in fields of power in which there may be little overt room for manoeuvre, the rallying points, the alliances, the compromises and the disappointments.

Our final section seeks to restore some of the complex richness of women's experience stripped away in the current reductionist logics. In doing so, we highlight a point that has been reinforced time and again by Pathways researchers: that empowerment is a journey, rather than a product. It is a journey that involves constant negotiation and compromise, with uncertain outcomes. Our research reveals pathways of empowerment that lie beyond the conventional gaze of development agencies. These reveal other dimensions of empowerment in aspects of women's lives often obscured by the materialism of development: the solace of belief and the sociality of religious practice, the pleasures of leisure, and the centrality to women's lives of affective and supportive relationships with others.

In this introduction, we seek to draw out some of the dimensions and dilemmas of women's empowerment, and to explore their implications. We do so via a series of keywords that capture although they do not exhaust - the themes emerging from the articles in this IDS Bulletin.

\section{Context}

It is a well-accepted feminist dictum that women cannot be empowered by others: 'real' empowerment is something that women can only do for themselves (Rowlands 1997). Yet, while there is general acceptance of this axiom, there is less attention paid - to paraphrase Marx - to the fact that women's pathways of empowerment are pursued under conditions that are not of their own choosing. Development agencies often evoke images of empowered autonomous subjects, able to choose, make and shape their own directions of travel. In reality, very few of us have the capacity to make independent choices and to follow them through. These 'structures of constraint' referred to by Marx and usefully highlighted by many feminist economists (Folbre 1994; Kabeer 2008) restrict women's ability to choose their own paths. But also the very nature of empowerment is something far more contingent and contextual, and ultimately far less predictable than the quick fit solutions, purveyed by development agencies, allow for.

Context is crucial in making sense of empowerment. Historical shifts in societal and cultural norms and practices, as well as in institutions in politics and the economy, current and previous political conjunctures, the density of donor engagement and the nature of the state, the broader landscape of organisations and social movements, and a number of other contextual factors impinge on the possibilities for women's empowerment - facilitating and enabling but also blocking and restricting possibilities. In this IDS Bulletin we explore a number of the 'solutions' that have become universalised by development agencies - quota systems to enhance women's political representation, education for girls, legal reforms aimed at securing or enhancing women's rights, support to civil society. These are examined against how they play out within the realities of women's lives in particular political, social and cultural contexts.

Articles by Hussainatu Abdullah, Aisha F. Ibrahim and Jamesina King; Akosua Darkwah; Penny Johnson; and Cecilia Sardenberg all highlight the significance of contextualising efforts to enhance women's empowerment in time as well as place. As Darkwah shows, for older generations of Ghanaian women education did provide a pathway of empowerment; but for younger women, the route map has changed, as have the means of enhancing their prospects in the contemporary labour market. Cecilia Sardenberg considers changes across generations of working class women in a Brazilian low- 
income neighbourhood, exploring how shifting expectations shape women's everyday lives and choices. Abdullah et al. show how vital history is to understanding women's struggles to gain visibility and voice. Penny Johnson's article poses the question of how we perceive the idea of empowerment in a context where prolonged warlike conditions are 'ordinary' and instability is the norm.

Terezinha Gonçalves' account of the gains made by the domestic workers' movement in Brazil illustrates precisely just how much context matters in understanding their significance, and the scope for achieving them. To understand the story of the domestic workers' movement, she points out, we need to recognise deep-rooted patterns of discrimination and exploitation from the era of slavery. Equally, to make sense of what the movement has achieved, we need to locate their activism in the current political conjuncture. Brazil's left-of-centre Workers' Party government has had a major influence on the gains secured by workers' movements of all kinds, especially the marginalised. To grasp just how significant these gains are, we need to know about the dynamics of difference in this context - gender, race and class - and the distinctive tensions and contradictions their intersection provokes. Gonçalves shows how these play out in all aspects of domestic workers' lives, from the workplace, to the home, to engagement with union, feminist and black movements.

\section{Choice}

Empowerment is not just about enlarging the boundaries of action. It is also about extending the horizons of possibility, of what people imagine themselves being able to be and do. Mainstream empowerment discourses reduce the complexity of this process to a simple equation, in which there is a linear connection between choice, action and outcome (Buvinic and King 2007).

The World Bank has enthusiastically promoted women's empowerment. In one publication, empowerment is defined as 'the process of enhancing an individual's or group's capacity to make purposive choices and to transform these choices into desired actions and outcomes' (Alsop et al. 2005: 120). The rich empirical material in this IDS Bulletin reveals some of the limitations of thinking about empowerment in such a linear way. First of all, outcomes are not always the direct result of choices. An outcome in terms of a change in the degree to which young women will be sexually harassed in the street calls for more than for those young women to 'choose' that change; and the action that manifests a 'choice' and produces that 'outcome' may be young women covering themselves up completely or not walking down the street on their own. This would hardly fall within most feminists' - or indeed the World Bank's - view of 'empowerment'.

A deliberate action that contravenes a social norm may constitute an act of empowerment. But such acts may or may not have any effect on the acts of others; similarly, they may or may not make any difference in the longer term to the situation either of the actor or of other women. Acts may have entirely unintended outcomes, just as outcomes may be produced by entirely unrelated acts. Actions presumed to lead to empowerment - taking a microcredit loan, for example - may simply sustain women in their existing situation. External interventions aimed at producing empowerment may, similarly, fail to achieve the desired results precisely because there is a failure to understand the social dimensions of constraint, as well as the cultural limits of 'choice' (Kabeer 2008). As Kalpana Wilson (2008) notes, within this there is a reduction of women's exercise of agency to strategies for individual self-improvement, rather than struggles for transformation - that which Cecilia Sardenberg (2009) dubs 'liberal' as opposed to 'liberating' empowerment.

Looking beyond the obvious, at hidden pathways of women's empowerment, becomes crucial if we are to understand change in women's lives. Samia Rahim and Aanmona Priyadarshani's account of what Bangladeshi slum women gain from watching television is a good example of what can be learnt by looking beyond deliberate efforts that are made to 'empower women' to what is happening in women's lives that is bringing about change. What comes to constitute a (potentially empowering) 'choice' is very context-specific. It depends not only on broader social, cultural, economic and political environments, but also on the circumstances of particular women. What is experienced as empowering by one woman is not necessarily going to be so for every woman; empowerment for one can be disempowerment for another. What may be available as a choice to one woman may be out of bounds for others, and it may be a matter of 
context whether certain kinds of choices can be constructed as 'empowering' at all.

Narratives of empowerment tend to evoke women taking power, doing what they please, shrugging off customs or constraints, making it for

themselves. And yet when we look more closely at women's pathways of empowerment, and at what 'choice' may actually mean in their everyday lives, a rather different picture emerges. In a number of articles in this collection, the kinds of 'choices' that are being made do not feature in the development narrative; we find pathways of empowerment that wend through settings such as a prayer group or an afternoon in front of the television. It is difficult for development agencies to countenance that, for example, the pleasures of leisure can be empowering. Sometimes what women actually want and do are not the paths development organisations hope women would tread. But it is important to recognise and respect women's own perspectives and decisions, even if they may not appear to outsiders to be empowering.

\section{Narratives}

How women are portrayed in literature, religion and the media deeply affects how they are perceived and treated. For all the affirmative tone that development agencies take when extolling women's role in uplifting and enriching their communities and societies, these popular representations tell a different story. They include the message that a woman's education is secondary to a man's, that her unmarried state is a crisis, that if she is good she devotes her life to her family, that violence against her is brought on by her own immorality and that her abuse is a weapon of war. Cropping up in a number of articles in this IDS Bulletin is the pervasive notion of what a 'good girl' or 'good woman' is and how she is expected to act; anything that kicks against these expectations is frowned upon, if not actively repressed.

International non-governmental organisations (NGOs), development banks and donors play into these narratives to sell themselves to their publics, and secure their legitimacy. Their use of the iconic image of the 'poor, powerless and pregnant' Third World woman (Mohanty 1988; Win 2004) may have given way to the smiling faces of 'empowered' women, but the narrative is still one in which the development agency plays the part of hero.

Women's organisations face difficult choices about how to portray women's issues. In reflections on the dilemmas faced by a Bangladeshi feminist $\mathrm{NGO}$ in getting the tone right in advocacy for acid victims, Nazneen and Sultan reflect on the challenges in this context of navigating between representations that play to a sympathy that can be elicited from viewing publics, and the need to show women not as victims but agents.

In a number of the articles in this IDS Bulletin, we begin to see the impact of broader societal change and social mobilisation on the way women are beginning to see themselves and engage critically with things they may before have taken for granted. Priyadarshani and Rahim's analysis of women watching television in Dhaka slums, documents conformity with normative ideals of women's position in society. They also reveal a desire among these women for more positive and powerful representations of women. Access to new technologies such as mobile phones and satellite television can bring moral danger - as in the example in Penny Johnson's article of the woman who is killed when doctored images of her are circulated by mobile phone. Yet it can also forge new pathways of empowerment, enabling women to learn and exercise tactics for negotiating power in their lives.

\section{Relationships matter}

Mainstream empowerment narratives tend to neglect relationships, focusing on individual women's trajectories of self-improvement or on the bigger picture of society-wide economic change. But women's lived experiences of empowerment cannot be understood adequately by approaches that atomise women, abstracting them from the social and intimate relations that constrain and make possible their empowerment or disempowerment (Kabeer 1998; Cornwall 2007). Naila Kabeer and Lopita Huq's article places relationships at the centre, showing how a social relationship with a women's organisation can prove stronger even than familial bonds. They tell of how a 'failed' NGO - the Bangladeshi women's organisation Saptagram was revived out of love for a group that had invested so much in building relationships with the women it worked with that they came to see it as a cherished part of their everyday lives. They cite one of these women, Rashida:

I have learnt how to stand on my own two feet from Saptagram, the value of unity, how to overcome 
problems, how to mix with people, how to sign my name. And I have learnt about our rights.

The quote is revealing. Being able to 'stand on my own two feet' is a familiar enough indicator of empowerment, but this is set alongside other gains such as the value of unity, how to mix with people, 'our rights'. It attests to a more relational than individualistic view of autonomy ( $c f$. MacKenzie and Stoljar 2000). Kabeer (1998) makes a vital point that is often forgotten by those who pick up more enthusiastically on her framework than on her analysis, cautioning against extracting women from the relational webs that constitute their social and economic lives.

Cecilia Sardenberg illustrates other relational dimensions that are important to factor into our understanding of empowerment. Writing about women in a low-income neighbourhood in Brazil, she shows how change can take place amidst apparent continuity, when women's perspectives on their own relationships and entitlements change. Sardenberg illustrates how a tradition of matrifocal domestic arrangements and female employment in this context has offered women a degree of power within an otherwise patriarchal culture. What has changed, she suggests, is women's own recognition of their position. In particular, women have come to recognise the limits of ideals of conjugal relationships that were part of their own discourse in this community a decade ago - and women are now freeing themselves from abusive relationships, and making their own decisions about where and whether to work, even if they face opposition from partners. Sardenberg's analysis attests to the significance of consciousness for women's empowerment. Indeed, she suggests, 'there seems to be a new discourse - a feminist discourse about women's roles and women's rights finding expression among working-class women in Brazil'. She also affirms the centrality of relationships, of the 'power with' that comes from being embedded in kin and community relationships, principally with women, which enable women to gain the power to act. The positivity in these female relationships for younger generations is clearly seen in Dona Nora's pronouncement that her granddaughter 'will be an Olympic champion'.

Relationships are also at the heart of the accounts of organisational and movement strategies that Nazneen and Sultan, and others such as Eyben,
Abdullah et al. and Gonçalves tell. A common thread running through these very different contexts and struggles is the significance of the kinds of relationships that can serve advocacy and mobilisation, in particular alliances and coalitions. What emerges is the strategic importance for feminist action of a multilayered constituency of potential allies, located within, as well as outside, government and other agencies for policymaking and implementation.

While a number of the articles in this IDS

Bulletin reveal pathways of empowerment in which development agencies have played scant if any part, several offer lessons about relationships that development agencies would do well to heed (cf. Eyben 2006). Among them is the need to look beyond the materiality of money to what it does for and to relationships. This point is well made in Kabeer and Huq's poignant tale of the neardemise of a much-loved organisation as a result of donors showering it with money that it could ill absorb. It is also made in Sholkamy's account of civil society organisations in Ain el-Sira, with their limited vision, reach and means. What is evident from many of the articles, is that it is relationships rather than assets that bring about the kinds of changes associated with 'empowerment' - such as growth in selfconfidence, capabilities and consciousness, and capacity to act collectively to demand rights and recognition. This seems almost self-evident, but it is a point that is easily missed in the reduction of empowerment to an equation in which certain 'inputs' will yield the desired outcomes in terms of economic growth, better-nourished children or other social or economic goods.

Relationships are, of course, far less visible and far less tangible than the measurable 'results' that donors seek. And yet without investments in creating an enabling environment that can not only support individual women to take up opportunities, but also address structural obstacles to more equitable gender relations, much if not most of what is done to promote women's empowerment stands little chance of making a sustainable difference.

\section{Voice}

Whether empowerment is conceptualised as individual journey or as collective struggle, both emphasise women finding and using their voice. There is as little disagreement among 
development actors about the need to promote women's political empowerment as there is with the benefits of women's economic empowerment (Eyben et al. 2008). Yet quite which women are the beneficiaries of empowerment interventions, who they represent and what they voice raises a host of thorny issues (Goetz and Nyamu Musembi 2008).

Much attention has been focused on the domain of formal politics, and on increasing the numbers of women in office. Quota systems are a relatively recent innovation - many dating from the period after the 1995 Fourth World Conference on Women held in Beijing, where the 30 per cent target for female representation in political office was set. ${ }^{3}$ Ana Alice Costa's article draws on Latin American experience to reflect on lessons learnt from the contrasting experiences of countries achieving relatively high proportions of women in public office and those where numbers remain very low. Quotas may get more women into political office, where they are implemented effectively - and that remains a huge challenge, as Costa points out. But changing politics calls for more than a few individual women finding a path into political office: as the slogan of the Argentinian political feminist network cited by Costa puts it, 'with a few women in politics, women change; with a lot of women in politics, politics change'.

For feminist and women's movements in many countries, the highly exclusionary, patriarchal arena of formal politics has often been one of the least promising pathways to power. Costa notes how few women have made it to the top on merit, rather than through family connections. Abdullah et al. show for Sierra Leone that women seeking political office have faced the obstacles not only of their gender, but also their class and family connections. One of the shifts they note is a widening of political opportunity beyond a clutch of privileged women. Their analysis shows the need to look more closely at the different arenas in which women's voices are elicited and listened to, and to think more critically about the extent to which opportunities to participate and influence in one arena translate into a broader willingness on the part of powerful institutions to listen to women. Their article tells a story, familiar from other contexts, of the role played by women's mobilisation and voice in Sierra Leone's struggle for peace, and women's marginalisation after the war was over. And yet, as they and other contributors show, there can be a cumulative effect of efforts to gain public and political space, as tactics are honed and networks are strengthened, lending women opportunities for political apprenticeship that they may otherwise be denied.

Development goals and targets have focused more attention on formal politics than on the myriad other spaces that exist for decisionmaking and influence. Male domination of spaces of decision-making power in the economic arena has come under greater scrutiny in recent years, making an appearance in this year's Davos Meeting as a key issue. Marginalised from formal institutions of politics and the economy, women's organising has not only happened outside these domains, but has often focused on other means of being heard: through movement building to gain public presence and influence public opinion, through engaging the media, and through alliances with other movements and, as Eyben points out, supportive bureaucrats. Nazneen and Sultan make an observation that holds for other settings. In their comparative analysis of three Bangladeshi women's organisations, they note how feminist and women's movements have been as reluctant to engage in party politics as they have been unsuccessful in engaging political parties with their concerns.

Lastly, an assumption is often made that there are more opportunities for women to gain a voice at the 'community' level - through community-based organisations (CBOs), women's groups and so on - and that these organisations are in a position to know and articulate what women need. Hania Sholkamy's account of NGOs and CBOs in a Cairo slum questions the presumption that civil society organisations are closer to the poor, participatory and more responsive than the state. She shows how duplication of effort can render intervention less effective. The programmes that are implemented are unsustainable and are not revised to adapt to changing circumstances. In Penny Johnson's article we see women's exasperation at being given the same information that agencies think they need rather than information on sexuality and their bodies, which is what they want. It seems that in all the fine talk about empowerment, participation has slipped off the agenda: and if women are to have a voice, far more needs to be done to engage them, at all levels, in the decisions that affect their lives. 


\section{Negotiation}

Seeing empowerment as a process of negotiation - one that may consist of subtle acts that increase women's room for manoeuvre as well as the overt exercise of agency - opens up the possibility of recognising the 'empowering' elements of acts that might at first sight appear 'disempowering'. Empowerment emerges from these studies as something that is less about clear-cut choices that are transformed into actions and outcomes, but more something that is at once more provisional and dynamic.

This emerges powerfully in Samia Huq's article, which explores the complexities of faith, religion and empowerment in Bangladesh. Huq looks at how women steer their path through the structures of religion and secularism, both challenging and incorporating aspects of them within their own expressions of agency. In doing so, she challenges orthodoxies about women and religion, and particularly the tendency to label women's engagement with religious practice as 'disempowering', with a subtle and powerful account of the negotiation of power and agency within the bounds of Islamic faith. Huq's analysis leads us to a series of important points.

Contestation may provide women less scope for the exercise of agency than tactical accommodation and, indeed, compromise; choices that transgress societal norms may be especially hard to make, with risks that are particularly high for women who can least afford to take them.

Penny Johnson's account of Palestinian women who choose education and work outside the home in preference to marriage shows just how tough these choices are, when set against a background of hard struggle against society's expectations. It is difficult for women to transgress social norms even in the most liberal of contexts. When they do, as Jaya Sharma (2009) points out, transgressions may be accompanied by compliance with certain norms in certain circumstances, as women negotiate precarious pathways through thickets of prejudice and constraint. It may be the case, that to be able to acquire certain freedoms, women need to subscribe to certain societal expectations - pretending to be or getting married, wearing certain kinds of clothing, keeping quiet instead of speaking up.

These negotiations are especially interesting for what they tell us about women's own assessment of opportunities and risks, and also for the way in which we make sense of their exercise of agency. These negotiations can be an essential part of women living their lives and achieving the most positive outcomes that they can from situations not of their own making. They can also make the difference between change happening, albeit at a gradual pace, than it not happening at all. The kind of change that we see in women's everyday lives is much more subtle, much more incremental, than that portrayed by development agencies in their narratives of empowerment. It is often necessary to work within existing strictures to achieve some positive gains, with the hope that these may eventually ripple out and bring about wider changes.

Rosalind Eyben picks up on this point in her exploration of the strategies and tactics used by feminist bureaucrats engaged in 'gender mainstreaming' in aid organisations, revealing some of the subversive tools feminist bureaucrats can draw on in negotiating empowerment within their organisations. Similarly, the journeys of negotiation, accommodation and compromise that women's organisations undertake as they seek out and build alliances are captured in Nazneen and Sultan and Gonçalves' articles. Together they offer rich accounts of the tactics that organisations may need to resort to in order to achieve small gains. These may include avoiding contentious issues and choosing battles you are surer to win, even if this means not confronting existing unequal structures head on. These negotiations may not only be with the state and structures, but may also be within alliances themselves as Nazneen and Sultan show; ultimately these alliances are important especially for being prepared to take nimble advantage of opportunities for intervention as they arise.

Emerging from these articles is a nuanced account of negotiation, accommodation and compromise that is a welcome corrective to representations that emphasise only the boldest conquests. They paint a rich picture of tactical engagement, but most of all, they highlight the complexities that are part of any process of social change.

\section{Conclusion}

The studies in this IDS Bulletin highlight a number of important issues. Mechanisms for promoting women's empowerment - quotas, education and training, credit, legal reforms - 
are necessary but not sufficient; they are a means, not an end in themselves. Context matters: the same solutions cannot be rolled out to every region without examining the realities of women's lives and what made them as they are. And the finest policies and laws mean nothing if no one is held to account for their nonimplementation. As Mulki Al-Sharmani notes:

Legal reforms (even the most emancipating ones) are not the end result. These reforms are only meaningful insofar as they actually lead to positive and substantive changes in the lives of those who are targeted by the new laws.

Pathways research suggests that significant changes in women's lives are taking place outside the range of conventional empowerment interventions. The kinds of experiences of empowerment and disempowerment that emerge from the articles in this collection highlight

\section{Notes}

* We would like to thank Rosalind Eyben, Mariz Tadros, Hazel Reeves, Cecilia Sardenberg and Tessa Lewin for their helpful comments on an earlier draft of this introduction.

1 For more information about the programme and for case studies, working papers, reports, links to video and audio resources and more, see www.pathwaysofempowerment.org

2 Pathways was established as a DFID Research Programme Consortium in 2006 and is funded

\section{References}

Alsop, R.; Heinsohn, N. and Somma, A. (2005)

'Measuring Empowerment: An Analytic Framework', in R. Alsop (ed.), Power, Rights and Poverty: Concepts and Connections, Washington DC: World Bank

Buvinic, M. and King, E.M. (2007) 'Smart Economics', Finance and Development 44.2: 7-12

Cornwall, A. (2007) 'Of Choice, Chance and Contingency: "Career Strategies" and Tactics for Survival Among Yoruba Women Traders', Social Anthropology/Anthropologie Sociale 15: 27-46 DFID (2006) Making Governance Work for the Poor, DFID White Paper, London: Department for International Development

Eyben, R. (2006) Relationships for Aid, London: Earthscan issues that have been neglected by development agencies, such as relationships, leisure, pleasure, love and care. Women's own voices, analyses, experiences and solutions continue to be disregarded in the rush for results. It is time that more attention was paid to them.

Perhaps most of all, what the articles in this IDS Bulletin emphasise is that empowerment is a complex process of negotiation, rather than a linear sequence of inputs and outcomes. Policies that view women as instrumental to other objectives cannot promote women's empowerment, because they fail to address the structures by which gender inequality is perpetuated over time. Rather than betting on a limited range of institutional interventions, governments and development agencies would do better investing in creating an enabling environment for women's empowerment, and supporting those who are tackling deeper-rooted issues of power that impede transformative change.

by DFID, the Norwegian Ministry of Foreign Affairs and the Swedish Ministry for Foreign Affairs. The Consortium supports research into women's empowerment in Afghanistan, Bangladesh, Brazil, Egypt, Ghana, India, Nigeria, Pakistan, Palestine, Sierra Leone and Sudan, and in global policy spaces.

3 See International IDEA for a number of excellent resources on electoral quotas for women: www.idea.int/gender/quotas.cfm (accessed 12 December 2009).

Eyben, R.; Kabeer, N. and Cornwall, A. (2008) Conceptualising Empowerment and the Implications for Pro-Poor Growth, paper for the DAC Poverty Network, Brighton: IDS

Folbre, N. (1994) Who Pays for the Kids? Gender and the Structures of Constraint, New York: Routledge

Goetz, A-M. and Nyamu Musembi, C. (2008) Voice and Women's Empowerment: Mapping a Research Agenda, Pathways Working Paper 2, Brighton: Pathways of Women's Empowerment RPC

Kabeer, N. (2008) Paid Work, Women's Empowerment and Gender Justice: Critical Pathways of Social Change, Pathways Working Paper 3, Brighton: Pathways of Women's Empowerment RPC

Kabeer, N. (1998) Money Can't Buy Me Love? Reevaluating Gender, Credit and Empowerment in 
Rural Bangladesh, IDS Discussion Paper 363, Brighton: IDS

MacKenzie, C. and Stoljar, N. (2000) Relational Autonomy: Feminist Perspectives on Autonomy, Agency and the Social Self, Oxford: Oxford University Press

Mohanty, C. (1988) 'Under Western Eyes: Feminist Scholarship and Colonial Discourses', Feminist Review 30: 61-88

Rowlands, J. (1997) Questioning Empowerment: Working with Women in Honduras, Oxford: Oxfam Publishing

Sardenberg, C. (2009) Liberal vs Liberating Empowerment: Conceptualising Women's
Empowerment from a Latin American Feminist Perspective, Pathways Working Paper 7, Brighton: Pathways of Women's Empowerment RPC

Sharma, J. (2009) 'Reflections on the Construction of Heteronormativity', Development 52.1: 52-5

Wilson, K. (2008) 'Reclaiming "Agency", Reasserting Resistance', IDS Bulletin 39.6: 83-91

Win, E. (2004) 'Not Very Poor, Powerless or Pregnant: The African Woman Forgotten by Development', IDS Bulletin 35.4: 61-4 